\title{
Intralanguage vs. interlanguage Stroop effects in two types of writing systems
}

\author{
SHENG-PING FANG \\ University of California, Riverside, California 92521 \\ OVID J. L. TZENG \\ Haskins Laboratories, New Haven, Connecticut 06510 and University of California, \\ Riverside, California 92521 \\ and \\ LIZ ALVA \\ Abt Associates, Cambridge, Massachusetts 02137
}

\begin{abstract}
The relation between word processing strategy and the orthographic structure of a written language was explored in the present study. Three experiments were conducted using ChineseEnglish, Spanish-English, and Japanese-English bilinguals, respectively. Each subject was asked to perform a modified Stroop color-naming task in which the stimulus and the response language were either the same or different. The magnitude of the Stroop effect was greater in the intralanguage condition than in the interlanguage condition. When the magnitude of reduction of Stroop interference from the intra- to the interlanguage condition was compared across all bilingual groups, an inverse relationship was found between the magnitude of reduction and the degree of similarity between the orthographic structures of the two written languages. It is concluded that reading logographic and reading phonetic aymbols entail different processing mechanisms and that controversial issues in bilingual processing cannot be resolved without taking into account the effect of orthographic variations on the information processing system.
\end{abstract}

The invention of written symbols to represent spoken language is undoubtedly one of the most important achievements in the history of mankind. The written symbol has enabled us to overcome the limitations of space and time imposed by oral communication and has allowed us to extend our thoughts across centuries as well as continents.

There have been many different types of writing systems invented to represent various types of spoken languages. The designing principles for writing systems can be divided into two different categories. The first type of orthography evolved from the earlier semasiography, which expresses a general idea in picture drawings rather than a sequence of words in a sentence, to logographs with each symbol expressing a single particular morpheme. The concept underlying the

We thank Jessie S. H. Deou and Susan Stone for their great help in conducting the third experiment and Katherine Malley for her helpful comments on earlier drafts. The final version of this paper has also benefited from comments made by Irving Biederman and the reviewers. The present study was supported in part by an Inter-Campus Research Fund from the Academic Senate of the University of California, Riverside, to the second author, and in part by a traineeship from the National Institute of Mental Health to the third author (supervised by Robert Singer). development of this type of orthography is to map the written symbols directly onto meaning. The second type of orthography evolved from the rebus (a representation of a word or phrase by pictures that suggest how a word is pronounced in the spoken language; see Figure 1) to the syllabary and then to the alphabet. The concept behind it is sound writing. That is, the relation of sign to meaning is meant to be mediated through the sound system of the spoken language. This difference in how lexical units may be recovered from written symbols raises an important and interesting question: Do our visual information processing strategies differ when the information is presented in different formats? In recent years, this question has become of major concern among many cognitive psychologists (Biederman \& Tsao, 1979; Gleitman \& Rozin, 1977; Park \& Arbuckle, 1977; Tzeng, Hung, \& Garro, 1978).
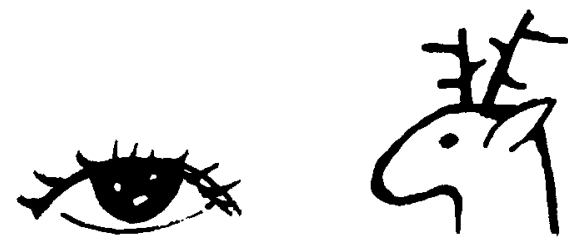

Figure 1. Rebus representing “idea." 
That reading different writing systems may entail different information processing strategies is supported by some recent clinical and experimental observations. Sasanuma (1974) reported that the ability of Japanese aphasic patients to use logographic (Kanji) and phonetic (Kana) scripts can be selectively impaired. Parallel to this finding, in visual hemifield experiments, in which stimuli are presented to the right or left visual field briefly via a tachistoscope, a right visual field (i.e., left-hemisphere) advantage is usually found for the recognition of phonetically based symbols such as English words or Japanese Kana scripts, whereas a left visual field advantage is found for the recognition of single Chinese characters (Tzeng, Hung, Cotton, \& Wang, 1979). Furthermore, in a cross-language study that investigated the effects of language (Chinese vs. English) and mode of stimulus presentation (visual vs. auditory), Turnage and McGinnies (1973) found that visual input facilitated the learning for Chinese subjects, whereas auditory input produced superior recall performance for American subjects. All these results seem to point out that readers of different scripts may have developed different processing strategies in order to achieve efficient reading. It is of utmost importance for cognitive psychologists to find out at which level of information processing these differences due to orthographic variations occur.

A recent study of Biederman and Tsao (1979) shed light on the issue of the orthographic variations by using a Stroop (1935) interference paradigm. The interference in the Stroop color-word test is the greater time required to name a series of color patches when the patches are themselves incongruent color names (e.g., GREEN in red ink) than when the patches are simple colored rectangles. Biederman and Tsao (1979) found a greater interference effect for Chinese subjects in a Chinese-version Stroop color-naming task than for American subjects in an English version. They attributed this difference to the possibility that there may be fundamental differences in the perceptual demands of reading Chinese and English. Since the perception of color and the direct accessing of meaning from a pattern's configuration are functions that have been assigned to the right hemisphere, it was suggested that during the Stroop test these two functions might be competing for the same perceptual capacity of the right hemisphere. This competition could have been avoided in the English Stroop test because reading English and naming colors are executed by different hemispheric mechanisms. Biederman and Tsao further speculated that there may be some fundamental differences in the obligatory processing of Chinese and English prints. They suggested that a reader of alphabetic writing cannot refrain from applying an abstract rule system to the word, whereas a reader of Chinese may not be able to refrain from configurational processing of the logograph.

The conceptualization that reading different types of scripts automatically activates different types of per- ceptual constraints is an intriguing one. It leads to a prediction concerning the bilingual processing in a modified Stroop task. Suppose a Spanish-English bilingual subject is asked to name colors once in each of the two languages for color stimuli that are either Spanish color words, English color words, or control patches. Based on previous empirical findings (Dyer, 1971; Preston \& Lambert, 1969), it is expected that colornaming speed will be relatively slower when the naming language and the language of the color words are the same than when they are different. In other words, the magnitude of Stroop interference will be lower in the interlanguage condition compared with the intralanguage condition. But since both Spanish and English are alphabetic scripts, which tend to activate similar obligatory processing strategies, the magnitude of reduction in Stroop interference would be relatively modest compared with a comparable Chinese-English task. For the Chinese-English bilingual subjects, it is again reasonable to predict that the interlanguage condition will produce less Stroop interference than the intralanguage condition. However, the important question is whether the magnitude of reduction (from the intra- to the interlanguage condition) will be greater, equivalent, or less for the Chinese-English bilinguals compared with that for the Spanish-English bilinguals. According to Biederman and Tsao's (1979) conjecture that reading alphabetic and logographic scripts entails different perceptual demands, one would predict that the magnitude of reduction (i.e., from the intra- to the interlanguage condition) should be greater for the Chinese-English bilinguals than for the Spanish-English bilinguals. This expectation results from the assumption that while English and Spanish scripts activate similar obligatory processing strategies and thus are competing for the same perceptual demands, the Chinese and English scripts activate different obligatory processing strategies, which do not interfere with each other. Experiments 1 and 2 were conducted to test this unique prediction generated from the considerations of orthographic variations and their relations to human information processing. Experiment 3 was conducted to further test this prediction while holding the phonological factor constant by using Japanese-English bilingual subjects.

\section{EXPERIMENTS 1 AND 2}

\section{Method \\ Experiment 1. Subjects. Thirty Chinese-English bilinguals with normal color vision served as subjects. All were students at the University of California. Twenty of them were recruited from the Riverside campus, and the remaining 10 were from the Berkeley campus. All subjects had learned Chinese as their first language. All of them had passed the Test of English as a Foreign Language (TOEFL) before they were admitted into the University of California. Based upon their naming latencies of English and Chinese color terms (printed in black ink), all of them should be classified as Chinese dominant.}

Materials. Three stimulus boards were prepared: one control 
board, one color-word board in English, and one color-word board in Chinese. Each board measured $40.6 \times 50.8 \mathrm{~cm}$.

The control board was constructed with six rows of 10 $3 \times 3 \mathrm{~cm}$ patches, the colors of which were red, blue, green, or brown. The patches were spaced $2 \mathrm{~cm}$ apart within each row, and the rows were spaced $3 \mathrm{~cm}$ apart. Among the 60 patches, each of the four colors appeared 15 times in a random arrangement except that no color ever appeared twice in succession.

On the English board, the color arrangement was identical to that on the control board, except that each patch was replaced with an English word indicating an incongruent color name. Due to the physical nature of English words, each color word was $1.5 \mathrm{~cm}$ tall and up to $3 \mathrm{~cm}$ wide, centered in the place where the patch would have been. Words and colors used on this board were red, blue, green, and brown (note that they are all monosyllabic words). Each word and color appeared 15 times randomly, and no word or color appeared twice in succession.

The Chinese board resembled the English version in all aspects except that each English word was transformed into its corresponding Chinese character and measured $3 \times 3 \mathrm{~cm}$. The characters used on the Chinese board were Characters $1-4$ in Figure 2, which represent red, blue, green, and brown, respectively. The Chinese characters are monosyllabic in nature.

Design and Procedure. Each subject was given six tasks: (1) color naming of patches in English, (2) color naming of patches in Chinese, (3) color naming of English color words in English, (4) color naming of English color words in Chinese, (5) color naming of Chinese color words in English, and (6) color naming of Chinese color words in Chinese. The order of administration was random.

Before the experiment started, the subject sat in front of a table while the stimulus board was placed on it, covered with a heavy blank paper sheet. The experimenter first explained the task and procedure to the subject. The subject was asked to perform each task as accurately and as quickly as possible and to correct mistakes whenever possible. The subject was also asked not to point at the items while naming their colors. It was especially emphasized not to read the words but to name the colors of them instead. The subject was then asked to respond to two practice items, one Chinese character (Charac-

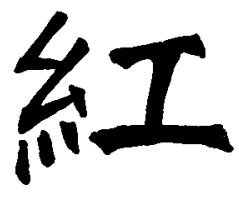

1

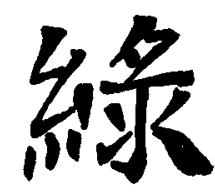

3

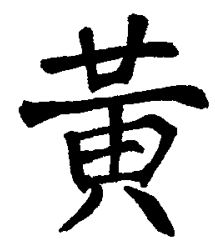

5

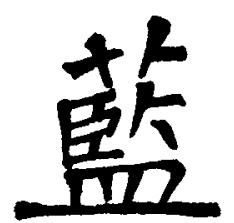

2

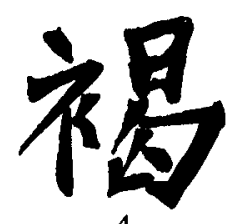

4

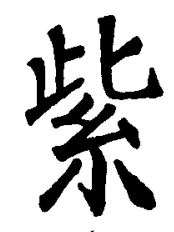

6
Figure 2. Chinese characters used in Experiment 1. ter 5 in Figure 2, which represents yellow) in pink ink and another character (Character 6 in Figure 2, which represents purple) in yellow ink. After proper responses were made, the experiment started. Each time a stimulus board was to be displayed, the subject was informed of the type of task to be performed. The stimulus board was covered again as soon as the task was completed. Color-naming times for entire boards were recorded with a stopwatch to the nearest .1 sec. Time between tasks was minimal, representing only the delay required to record data and obtain the new stimulus board.

Experiment 2. Subjects. Thirty Spanish-English bilinguals with normal color vision served as subjects. All had learned Spanish as their first language. Half of them were Spanish dominant and the other half were English dominant by their own estimates. However, based upon their naming latencies of English and Spanish color words (printed in black), all of them should be classified as Spanish dominant.

Materials. Three stimulus boards were used in Experiment 2, namely, one control board, one English color-word board, and one Spanish color-word board. Both the control board and the English board were identical to those used in Experiment 1. The Spanish board resembled its English counterpart in all aspects except that each English word was transformed into its Spanish equivalent. The Spanish equivalents were "rojo," "azul," "verde," and "café."

Design and Procedure. Each subject was given six tasks: (1) color naming of squares in English, (2) color naming of squares in Spanish, (3) color naming of English color words in English, (4) color naming of English color words in Spanish, (5) color naming of Spanish color words in English, and (6) color naming of Spanish color words in Spanish. The order of administration was random. The instruction and procedure were the same as those in Experiment 1. Color-naming times for entire boards were recorded with a stopwatch to the nearest $.1 \mathrm{sec}$.

\section{Results and Discussion}

For each subject, the color-naming time for the entire board was transformed into the naming time for a single item in milliseconds. This transformation procedure was applied to each of the six tasks, and then the mean color-naming time for each of the six tasks was calculated based upon these transformed scores across the whole group. The data of the Chinese-English bilinguals are presented in Table 1 (Experiment 1), and the data of the Spanish-English bilinguals are presented in Table 2 (Experiment 2). Note that scores in the columns labeled "I" represent the magnitude of the Stroop interference effect.

At first glance, the data presented in Table 1 seem to suggest that English color words produce greater Stroop interference $(492 \mathrm{msec})$ than Chinese color characters $(402 \mathrm{msec})$, a result at odds with that obtained by Biederman and Tsao (1979). However, a careful reflection reveals that this comparison between our data and those of Biederman and Tsao may not be a valid one. In the present experiment, English was the second language for our subjects, whereas in Biederman and Tsao's experiment English was the native language for their American subjects. Thus, the data, as shown in Table 1, should not be taken as an instance of failure to replicate Biederman and Tsao. In fact, our concern here is not to compare the degrees of interference between Chinese Stroop tasks and English Stroop tasks. Rather, the concern is with whether or not English and Spanish 
Table 1

Mean Color-Naming Times on the Stroop Tasks ( $T$, in Milliseconds per Item) for Chinese-English Bilinguals

\begin{tabular}{|c|c|c|c|c|c|c|}
\hline \multirow[b]{2}{*}{ Response } & \multicolumn{2}{|c|}{$\begin{array}{c}\text { English } \\
\text { Color Word }\end{array}$} & \multicolumn{2}{|c|}{$\begin{array}{c}\text { Chinese } \\
\text { Color Word }\end{array}$} & \multirow{2}{*}{$\begin{array}{c}\text { Control } \\
\text { Square } \\
\mathrm{T}\end{array}$} & \multirow{2}{*}{$\begin{array}{c}\text { Mean } \\
\text { I }\end{array}$} \\
\hline & $T$ & I & $\mathrm{T}$ & I & & \\
\hline English & 1431 & 605 & 1128 & 302 & 826 & 454 \\
\hline Chinese & 1098 & 378 & 1221 & 501 & 728 & 440 \\
\hline Mean & & 492 & & 402 & & \\
\hline
\end{tabular}

Note $-N=30 . I=$ the amount of interference (color word minus control square).

Table 2

Mean Color-Naming Times on the Stroop Tasks ( $T$, in Milliseconds per Item) for Spanish-English Bilinguals

\begin{tabular}{|c|c|c|c|c|c|c|}
\hline \multirow[b]{2}{*}{ Response } & \multicolumn{2}{|c|}{$\begin{array}{c}\text { English } \\
\text { Color Word }\end{array}$} & \multicolumn{2}{|c|}{$\begin{array}{c}\text { Spanish } \\
\text { Color Word }\end{array}$} & \multirow{2}{*}{$\begin{array}{c}\text { Control } \\
\text { Square } \\
\mathbf{T}\end{array}$} & \multirow{2}{*}{$\begin{array}{c}\text { Mear } \\
\text { I }\end{array}$} \\
\hline & $\mathbf{T}$ & I & $T$ & I & & \\
\hline English & 1169 & 495 & 1017 & 343 & 674 & 419 \\
\hline Spanish & 1166 & 446 & 1110 & 398 & 720 & 418 \\
\hline Mean & & 470 & & 366 & & \\
\hline
\end{tabular}

Note $-N=30 . I=$ the amount of interference (color word minus control square).

words (both being alphabetic scripts) would activate the same processing mechanism such that switching languages in a bilingual Stroop task should not reduce the amount of interference as much as in the case of switching between English and Chinese (a logographic script).

But before we examine the data pertinent to the above concern, let us clarify one particular point about the rationale behind the methodology. It can be argued that in no situation do subjects visually process words in the two languages simultaneously and that we may have a confusion between input (reading) and output (naming) mechanisms. Consequently, one may ask on what basis are we assuming that reading and naming engage the same mechanisms. This assumption can be supported by recent empirical research on graphemic recoding. First, an automatic speech recoding of visually presented words is an established fact, and it occurs in processing words written in alphabetic as well as nonalphabetic (such as Chinese, Japanese, etc.) scripts (Erickson, Mattingly, \& Turvey, 1977; Tzeng, Hung, \& Wang, 1977). Second, an automatic graphemic recoding of auditorily presented words has recently been established in a series of experiments by Nolan, Tanenhaus, and Seidenberg (in press) and Seidenberg and Tanenhaus (1979). More important, further studies on the graphemic recoding phenomenon by Tanenhaus, Flanigan, and Seidenberg (1980) demonstrated that such an automatic graphemic recoding was responsible for slowing down color-naming responses in a Strooplike task. Similar findings were also reported by Conrad (1978). Therefore, our assumption that the orthographic factor is involved in a color-naming task has some empirical support.

Let us now examine the data presented in Tables 1 and 2 with respect to predictions made earlier in this paper. First of all, the Stroop interference effect was indeed reduced in the interlanguage condition compared with that in the intralanguage condition. There was a $213-\mathrm{msec} / \mathrm{item}$ reduction for the Chinese-English bilinguals and a 48-msec/item reduction for the SpanishEnglish bilinguals. And indeed, the magnitude of reduction appeared greater for the former than for the latter.

A one-tailed planned comparison between inter- and intralanguage Stroop effects was made for both bilingual groups. The magnitude of shift-language reduction was significant for the Chinese-English subjects, but not for the Spanish-English subjects $[\mathrm{t}(29)=6.08, \mathrm{p}<.0001$, and $\mathrm{t}(29)=1.48, \mathrm{p}<.10$, respectively]. Thus, the main prediction was confirmed. That is, the reduction scores of the two groups did differ significantly, and the magnitude of reduction was greater for the ChineseEnglish bilinguals than for the Spanish-English bilinguals.

For each bilingual group, a repeated-measures analysis of variance was also performed with the stimulus language as one factor and the response language as the second factor. For the Chinese-English subjects, the main effect for the stimulus language was significant $[F(1,29)=$ $6.35, \mathrm{MSe}=38,225, \mathrm{p}<.05]$, whereas the main effect for the response language was not $[F(1,29)<1]$. Also significant was the interaction between the two factors $[F(1,29)=36.94, \mathrm{MSe}=36,697, \mathrm{p}<.001]$. Further analysis of simple effects showed that there was significantly less interference whenever response and stimulus languages were different compared with the cases when they were the same. For the Spanish-English subjects, the only significant effect found was the main effect of the stimulus language $[F(1,29)=13.52, \mathrm{MSe}=24,031$, $p<.001]$, with English color words resulting in greater interference than Spanish color words in both response conditions.

For both Spanish-English and Chinese-English subjects, the stimulus language had much stronger control over the degree of interference than the response language did. Both groups exhibited a significant main effect of the stimulus languages, whereas in both groups, response languages accounted for essentially none of the total variance. These results suggest that the bilingual Stroop effect is more likely to be at the perceptual level than at the response level. The emphasis on the stimulus factor is in line with Biederman and Tsao's (1979) conjecture that the orthographic structure in the written language may play an important role in determining the magnitude of the Stroop effect. Biederman and Tsao also localize such an orthographic effect at the perceptual stage. They reason that different orthographic structures may impose different task demands, such that different perceptual mechanisms are activated to meet these demands. This conceptualization also helps to explain the results of the two bilingual groups. Since both 
English and Spanish are alphabetic scripts, the perceptual mechanisms activated to process them are similar. Consequently, switching languages would not reduce the Stroop effect. On the other hand, Chinese logographs and English letters are two different scripts; switching language means turning off one perceptual mechanism and turning on another one, such that little interference would occur.

Based upon the above observations, we may offer a more generalized statement about the effect of the orthographic structure on bilingual Stroop interference. That is, for any group of bilingual subjects, the magnitude of reduction from the intra- to the interlanguage Stroop interference effect is a linearly decreasing function of the degree of similarity between the orthographic structures of the two languages. The validity of such an assertion can be tested by examining the patterns of the bilingual Stroop effects in the existing literature. To do this, we recalculated from the results of the present experiment and two other different bilingual experiments the magnitude of reduction of the Stroop interference from the intra- to the interlanguage condition (Dyer, 1971, Experiment 2, Session 1; Preston \& Lambert, 1969). All together, there were five types of bilingual subjects, namely, Chinese-English, HungarianEnglish, Spanish-English, German-English, and FrenchEnglish. Whenever more than one experiment was run with respect to a certain type of bilinguals, data were combined for that bilingual condition. We ranked these reduction scores according to their magnitude and obtained the following results (Table 3): ChineseEnglish bilinguals revealed a per-item reduction of $213 \mathrm{msec}$; Hungarian-English; $112 \mathrm{msec}$; Spanish-English, $68 \mathrm{msec}$; German-English, $36 \mathrm{msec}$; and French-English, $33 \mathrm{msec}$. The ordering of the last three categories is particularly revealing. Why should switching between Spanish and English produce a greater reduction of interference than switching between French and English or between German and English? It is certainly not intuitively obvious why Spanish and English are more orthographically dissimilar than French and English (or German and English). However, if we examine the spellings of color terms across these languages, then the deviation of Spanish becomes immediately clear. For

Table 3

Mean Reduction of Stroop Interference (in Milliseconds per Item) From the Intralanguage to the Interlanguage Condition for Six Types of Bilingual Subjects From the Present Study and From Experiments by Dyer (1971) and Preston and Lambert (1969)

\begin{tabular}{lr} 
Chinese-English & 213 \\
Kanji-English* & 121 \\
Hungarian-English & 112 \\
Hirakana-English* & 108 \\
Spanish-English & 68 \\
German-English & 36 \\
French-English & 33 \\
\hline
\end{tabular}

*Data from Experiment 3. example, "red," "blue," "green," and "brown" are translated and spelled as "rot," blau," "grün," and "braun" in German, as "rouge," "bleu," "vert," and "brun" in French, but as "rojo," "azul," "verde," and "café," respectively, in Spanish. Clearly, with respect to the color terms used in all these studies, Spanish color terms are orthographically more dissimilar to English color terms than both French and German are. Correspondingly, we also observed a greater reduction of Stroop interference. This pattern confirms our expectation that the magnitude of reduction is a negative function of the degree of similarity between the orthographic structures of the two written languages. In other words, the greater the orthographic similarity between the two languages, the stronger will be the competition for the same processing mechanisms and, thus, the smaller will be the reduction of Stroop interference from the intra- to the interlanguage condition.

However, since orthographic similarity is highly correlated with phonological similarity, an alternative explanation is to attribute the effect of switching language to the phonological factor instead of the orthographic factor. Even though these two explanations are not necessarily mutually exclusive, it is important to determine which factor (orthographic or phonological) contributes more to the reduction of the Stroop interference. Experiment 3 was conducted to weigh the importance of the orthographic factor while holding the phonological factor constant.

\section{EXPERIMENT 3}

To answer the question of whether the orthographic difference alone can account for the lexical processing and, consequently, for the differential shift-language effects observed in the last two experiments, JapaneseEnglish bilingual subjects were tested in Experiment 3.

Japanese is unique in the sense that three different types of scripts are concurrently used to represent the spoken language. Among the three types of scripts, Chinese logographs, generally referred to as Kanji, are generally used to write the content words. The other two kinds of scripts, which are referred to as hirakana and katakana, are syllabic in nature, and are used for writing grammatical particles and foreign words, respectively. Although these three types of scripts differ in their writing styles, the words written with any one of the scripts are read in exactly the same pronunciation. This unique aspect of Japanese writing enables us to vary the orthographic structures while holding the phonological factor constant.

In this experiment, color words were written in Kanji, hirakana, or English. With respect to the script/speech relationship embedded in the orthographic structure of the writing system, the hirakana script as a soundwriting system bears closer relation to the English script than the Kanji logograph does. Following the arguments advanced by Biederman and Tsao (1979), it is reasonable 
to assume that the hirakana and English scripts are more likely to share a common processing mechanism than are the Kanji and English scripts. Accordingly, if the orthographic factor alone can effectively account for the differential reduction scores observed in Experiments 1 and 2, then the magnitude of reduction (from the intra- to the interlanguage condition) should be significantly greater for the Kanji-English condition than for the hirakana-English condition. On the other hand, if the phonological factor plays a more important role, then little difference in the magnitude of reduction should be observed between the Kanji-English and the hirakana-English condition. Of course, there is always the possibility that both factors may play determinant roles in the bilingual Stroop effect.

What about the direct comparison between the pure cases (i.e., no language switching) of Kanji and hirakana conditions? Biederman and Tsao (1979) demonstrated that more Stroop-type interference occurred in logographic than in alphabetic scripts. However, their demonstration required a comparison of two very different subject populations. In the present experiment, with Kanji and hirakana scripts as the experimental materials, we were able to draw subjects from one population and assign them randomly to two different conditions. Any demonstrated effect of orthography on the magnitude of the Stroop interference, therefore, should not be attrib. uted to the subject factor.

\section{Method}

Subjects. Fifty Japanese-English bilingual students with normal color vision served as subjects. They were all natives of Japan and had at least 6 years of formal training in English as a second language. Most of them were enrolled in the ESL (English as a second language) Extension program and had been in the U.S. for less than 1 year. Thirty-eight subjects were tested at the University of California, Riverside campus, and the remaining 12 were tested at the University of California, Berkeley campus. Subjects at both campuses were randomly divided into two groups. Group 1 was exposed to color words in Kanji and English, and Group 2 was exposed to color words in hirakana and English.

Materials. Four stimulus boards were prepared: one control board, one color-word board in English, one color-word board in hirakana, and one color-board in Kanji. For the consistency of grammatical form in Japanese, the four colors and color names used in this experiment were red, blue, green, and purple. Both the control board and the English board resembled those used in Experiments 1 and 2, except that the color and the word "brown" were replaced with purple in all cases. The hirakana board resembled the English version in all aspects except that each English word was transformed in to hirakana. The hirakana equivalents were "aka," "auo," "midori," and "murasaki" (Characters 1-4 in Figure 3), representing red, blue, green, and purple. Their Kanji counterparts were $3 \times 3 \mathrm{~cm}$ large and were Characters 5 (red), 6 (blue), 7 (green), and 8 (purple) in Figure 3. The control board, the English board, and the Kanji version composed the stimuli for Group 1 . The control board, the English board, and the Kana version composed the stimuli for Group 2.

Design and Procedure. Subjects were randomly divided into two groups. All subjects were asked to perform the following four tasks: (1) color naming of squares in English, (2) color

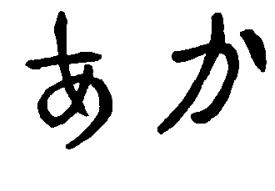

1

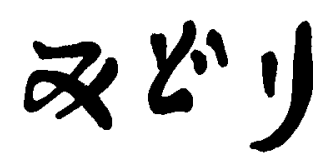

3

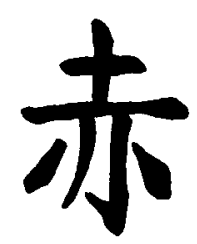

5

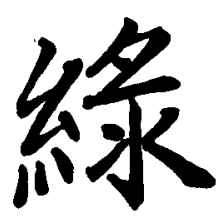

7

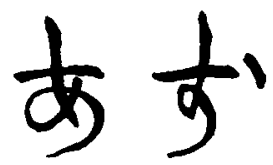

2

4

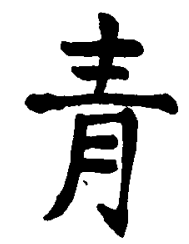

6

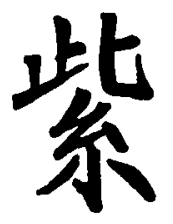

8

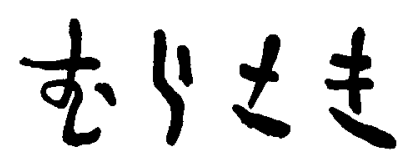

Figure 3. Japanese characters used in Experiment 3.

naming of squares in Japanese, (3) color naming of English color words in English, and (4) color naming of English color words in Japanese. Two additional tasks were assigned to Group 1 subjects: (5) color naming of Kanji in English, and (6) color naming of Kanji in Japanese. Similarly, subjects in Group 2 were asked to perform two additional tasks: (5) color naming of hirakana in English, and (6) color naming of hirakana in Japanese. The order of administration was random within each group and yoked between groups. The instruction and procedures were the same as those in Experiments 1 and 2. Color-naming times for entire boards were recorded with a stopwatch to the nearest $.1 \mathrm{sec}$.

\section{Results and Discussion}

Color-naming times for the entire card board were again transformed into reaction times of naming a single item in milliseconds. Table 4 shows the mean reaction times required for performing the six tasks. The scores of the Stroop effect, shown in the columns labeled "I," were analyzed separately for Group 1 and Group 2.

The scores of Stroop interference obtained from Group 1 were subjected to a repeated two-way ANOVA that examined the effect of the stimulus language and that of the response language. Statistical analysis revealed that the main effect of the stimulus language was significant $[F(1,24)=8.11, \mathrm{MSe}=20,083, \mathrm{p}<.01]$, whereas the main effect of the response language was not $[F(1,24)=3.03, \mathrm{MSe}=32,514]$. There was also a 
Table 4

Mean Color-Naming Times on the Stroop Tasks ( $T$, in Milliseconds per Item) for Japanese-English Bilinguals

\begin{tabular}{|c|c|c|c|c|c|c|c|c|c|c|c|c|}
\hline \multirow[b]{3}{*}{ Response } & \multicolumn{6}{|c|}{ Group $1(\mathrm{~N}=25)$} & \multicolumn{6}{|c|}{ Group $2(\mathrm{~N}=25)$} \\
\hline & \multicolumn{2}{|c|}{$\begin{array}{c}\text { English } \\
\text { Color Word }\end{array}$} & \multicolumn{2}{|c|}{$\begin{array}{c}\text { Kanji } \\
\text { Color Word }\end{array}$} & \multirow{2}{*}{$\begin{array}{c}\text { Control } \\
\text { Square } \\
\mathbf{T}\end{array}$} & \multirow{2}{*}{$\begin{array}{c}\text { Mean } \\
1\end{array}$} & \multicolumn{2}{|c|}{$\begin{array}{c}\text { English } \\
\text { Color Word }\end{array}$} & \multicolumn{2}{|c|}{$\begin{array}{c}\text { Kana } \\
\text { Color Word }\end{array}$} & \multirow{2}{*}{$\begin{array}{c}\text { Control } \\
\text { Square } \\
\text { T }\end{array}$} & \multirow{2}{*}{$\begin{array}{c}\text { Mean } \\
\text { I }\end{array}$} \\
\hline & $T$ & I & $\mathrm{T}$ & I & & & $\mathrm{T}$ & I & $\mathrm{T}$ & I & & \\
\hline English & 994 & 290 & 954 & 250 & 704 & 270 & 990 & 269 & 928 & 207 & 721 & 238 \\
\hline Japanese & 913 & 232 & 1115 & 434 & 681 & 333 & 910 & 221 & 1064 & 375 & 689 & 298 \\
\hline Mean & & 261 & & 342 & & & & 245 & & 291 & & \\
\hline
\end{tabular}

Note $-I=$ the amount of interference (color word minus control square).

significant interaction effect between the stimulus and response languages $[F(1,24)=13.67, \mathrm{MSe}=27,016$, $\mathrm{p}<.005]$. Further analysis suggested that the interaction resulted mainly from Kanji scripts' being exceptionally interfering when subjects are naming in Japanese.

A similar ANOVA was carried out on data of Group 2 subjects. The statistical analyses revealed neither an effect of the stimulus language nor an effect of the response language $[\mathrm{F}(1,24)=3.11, \mathrm{MSe}=16,795$, and $\mathrm{F}(1,24)=2.00, \mathrm{MSe}=44,964$, respectively $]$. However, there was a significant interaction between these two factors $[F(1,24)=9.50, \quad \mathrm{MSe}=30,645, \quad \mathrm{p}<.01]$. Post hoc analysis of simple effects showed that when subjects were naming in English, English scripts interfered more than hirakana $[F(1,48)=4.98$, MSe $=9,930$, $\mathrm{p}<.05]$ and when subjects were naming in Japanese, hirakana interfered more than English $[F(1,48)=30.04$, MSe $=9,930, p<.005]$. In the presence of hirakana, naming colors in Japanese was more difficult than naming them in English $[\mathrm{F}(1,48)=9.49, \mathrm{MSe}=37,804$, $\mathrm{p}<.005$ ], whereas naming colors in one language was not more difficult than naming them in the other when English words were presented $[\mathrm{F}(1,48)<1]$.

Of particular concern is whether differences in the orthographic structure play a decisive role in the magnitude of Stroop interference in a mixed-language condition. A one-tailed planned comparison between the intra- and the interlanguage condition was made for each of these two groups. The magnitude of shiftlanguage reduction was highly significant for both groups. There was a $121-\mathrm{msec} / \mathrm{item}$ reduction for Group 1 (Kanji) $[\mathrm{t}(24)=3.68, \mathrm{p}<.005]$ and a 108 $\mathrm{msec} /$ item reduction for Group 2 (hirakana) $[t(24)=$ $3.08, p<.005]$. However, the reduction scores of the two groups did not differ significantly, even though the direction of the difference was consistent with our expectation $[t(48)=.28$, n.s.]. Apparently, the phonological factors contribute more to the reduction of Stroop interference in the mixed-language condition than the orthographic factor does.

Another comparison was made between the two conditions in which both stimulus and naming languages were Japanese. Shimamura and Hunt (Note 1) conducted a Stroop experiment with color words written either in Kana or in Kanji (a within-subjects factor). They found a higher Stroop effect for Kanji than for
Kana script with Japanese subjects. In the present experiment, color naming in Japanese did appear more difficult for the Kanji version than for the Kana version (434 vs. $375 \mathrm{msec}$ ). Again, the difference is in the right direction. However, the difference was not statistically significant $[\mathrm{t}(48)=.23$, n.s.] .

According to the above results, it does not seem that a strong explanation based upon variations in orthography has gained support in Experiment 3. Yet, the orthographic factor cannot be totally dismissed without some cautious comments. In all comparisons made between Kanji and hirakana processing, the direction of differences exhibited an expected pattern but the differences failed to reach a statistically significant level. However, we have noted that similar studies carried out in other laboratories (Shimamura \& Hunt, Note 1; Biederman, Note 2) with a more powerful design (within subjects instead of between subjects) and with other dependent measures (e.g., error rates) ${ }^{1}$ did report significant differences. Therefore, we think the orthographic factor does play a role, but it may not be as important as the phonological factor, in the bilingual Stroop experiment. ${ }^{2}$

A criticism has always been raised against the comparison of Kanji and Kana symbols in the color-naming task. For fluent readers of Japanese, the color terms they read in everyday life are usually expressed in Kanji script, and rarely in Kana. Hence, the greater interference observed for the Kanji script may be attributable to this familiarity factor. To counter such an argument, Shimamura and Hunt (Note 1) and Biederman (Note 2) presented further evidence showing that in a simple word-naming experiment (naming words printed in black), color terms written in Kana were actually named much faster than were color terms written in Kanji. Similar findings were reported by Feldman and Turvey (1980). So, although color terms are more frequently written in the Kanji form and although Kanji characters are more compact graphic representations of words in general, naming time was consistently less for the Kana characters. Thus, familiarity seems not to be a major factor in these results.

\section{GENERAL DISCUSSION}

In recent years, reading research has become a significant interdisciplinary endeavor with contributions from 
such diverse fields as anthropology, artificial intelligence, cognitive psychology, educational psychology, linguistics, and neuropsychology. The present study tackles the issue of word processing from a cross-language perspective. Since the way a spoken language is represented graphemically varies from language to language, it is essential to find out whether such orthographic variations impose different processing requirements on readers of different written scripts. Two questions are of particular concern in the present study. First, would different processing mechanisms be activated in reading the logographic and the alphabetic scripts? Second, does the particular pair of languages that a bilingual individual knows have a specific effect on the degree of language overlap? For instance, should ChineseEnglish bilinguals be considered qualitatively different from Spanish-English bilinguals with respect to their lexical representations?

The first question can be answered more or less in an affirmative manner. Indeed, the idea that reading logographic and phonetic symbols entails different cognitive strategies and processing mechanisms has been supported by studies concerning aphasia (Sasanuma, 1974), visual lateralization effects (Tzeng et al., 1979), quantity-comparison tasks (Besner \& Coltheart, 1979), and serial recall (Turnage \& McGinnies, 1973). Biederman and Tsao (1979) have suggested that there may be fundamental differences in the obligatory processing of alphabetic and logographic print. A reader of alphabet writing cannot refrain from applying an abstract rule system to the word, whereas a reader of Chinese cannot refrain from configurational processing of the logograph.

Answers to the second question are less unequivocal. On one hand, we see that a rough estimate of the magnitude of reduction in the Stroop effect in mixed-language conditions (as compared with pure-language conditions) from among seven different types of bilingual subjects exhibits an orderly relationship between the orthographic structure and the amount of reduction. On the other hand, experiments with the two types of Japanese scripts provide only minimal support for the predictions generated from the consideration of orthography. Nevertheless, we also noted that data from other similar studies did provide much stronger support. Thus, we may conclude that the orthographic structure does play an important role, independent of the phonological factor, in the lexical formation of a bilingual subject.

The implication of such orthographic and phonological effects for research in bilingual processing is clear. We simply cannot, or should not, lump data of different types of bilingual subjects together and attempt to come up with a general statement about the processing mechanism. It has been the common practice of investigators of bilingualism to talk about $\mathrm{L} 1$ (first language) and L2 (second language) without paying much attention to the degree of orthographic and phonological similarities between the two languages. It is possible that these similarity effects may be responsible for some of the inconsistencies in bilingual research. For example, there is currently a controversy as to the pattern of the hemispheric dominance in $\mathrm{L} 1$ and $\mathrm{L} 2$ of a bilingual subject. It is conceivable that a Spanish-English bilingual should show a very different cerebral lateralization pattern from that of a Chinese-English bilingual (Tzeng et al., 1979).

The relation between language and thought has been a topic of intensive investigation for hundreds of years. Delineation of script/speech relationships and discovery of how the orthographic variations affect our information processing system may open up a new possibility for specifying the nature of symbol/thought interactions.

\section{REFERENCE NOTES}

1. Shimamura, A., \& Hunt, E. Stroop interference tests with Kanji and Kana scripts. Unpublished paper, University of Washington, Seattle, 1978.

2. Biederman, I. Personal communication, June 1980.

\section{REFERENCES}

Besner, D., \& Coltheart, M. Ideographic and alphabetic processing in skilled reading of English. Neuropsychologia, $1979,17,467-472$.

Biedenan, I., \& Tsıo, Y.-C. On processing Chinese ideographs and English words: Some implications from Stroop-test results. Cognitive Psychology, 1979, 11, 125-132.

Conrad, C. Some factors involved in the recognition of words. In J. W. Cotton \& R. L. Klatzky (Eds.), Semantic factors in cognition. Hillsdale, N.J: Erlbaum, 1978.

DYER, F. N. Color-naming interferences in monolinguals and bilinguals. Journal of Verbal Learning and Verbal Behavior, 1971, 10, 297-302.

Erickson, D., Mattingly, I., \& Turvey, M. T. Phonetic activity and reading: An experiment with Kanji. Language and Speech, 1977, 20, 384-403.

Feldman, L. B., \& Turvey, M. T. Words written in Kana are named faster than the same words written in Kanji. Language and Speech, 1980, 23, 141-147.

Gleitman, L. R., \& Rozin, P. The structure and acquisition of reading: Relations between orthographies and the structure of language. In A. S. Reber \& D. L. Scarborough (Eds.), Toward a psychology of reading: The proceedings of the CUNY conferences. Hillsdale, N.J: Erlbaum, 1977.

Hatra, T. Differential processing of Kanji and Kana stimuli in Japanese people: Some implication from Stroop-test results. Neuropsychologia, 1981, 19, 87-93.

Nolan, S. D., Tanenhaus, M. T., \& Seidenberg, M. S. Multiple code activation in word recognition: Evidence from rhyming monitoring. Journal of Experimental Psychology: Human Learning and Memory, in press.

Park, S., \& ARbuckle, T. Y. Ideograms versus alphabets: Effects of script on memory in "biscriptual" Korean subjects. Journal of Experimental Psychology: Human Learning and Memory, 1977, 3, 631-642.

Preston, M. S., \& Lambert, W. E. Interlingual interference in a bilingual version of the Stroop color-word task. Journal of Verbal Learning and Verbal Behavior, 1969, 8, 295-301.

Sasanuma, S. Impairment of written language in Japanese aphasics: Kana versus Kanji processing. Journal of Chinese Linguistics, 1974, 2, 141-157. 
Seidenberg, M. S., \& Tanenhaus, M. K. Orthographic effects on rhyming. Journal of Experimental Psychology: Human Learning and Memory, 1979, 5, 546-554.

Stroop, J. R. Studies of interference in serial verbal reactions. Journal of Experimental Psychology, 1935, 18, 643-661.

Tanenhaus, M. K., Flanigan, H. P., \& Seidenberg, M. S. Orthographic and phonological activation in auditory and visual word recognition. Memory \& Cognition, 1980, 8, 513-520.

T8ao, Y.C., WU, M.F., \& Feusted, T. Stroop interference: Hemispheric difference in Chinese speakers. Brain and Language, 1981, 13, 372-378.

Turnage, T. W., \& McGinnies, E. A cross-cultural comparison of the effects of presentation mode and meaningfulness in shortterm recall. American Journal of Psychology, 1973, 86, 369-381.

Tzeng, O. J. L., Hung, D. L., Cotton, B., \& Wang, W. S. · Y. Visual lateralization effect in reading Chinese characters. Nature, 1979, 282, 499-501.

Tzeno, O. J. L., Hune, D. L., \& Garro, L. Reading the Chinese characters: An information processing view. Journal of Chinese Linguistics, 1978, 6, 287-305.

Tzeng, O. J. L., Huna, D. L., \& Wang, W. S.Y. Speech recoding in reading Chinese characters. Journal of Experimental Psychology: Human Learning and Memory, 1977, 3, 621-630.

\section{NOTES}

1. Biederman also suggested that we examine the error rates across Kanji and Kana conditions. We did keep the records of errors in each condition. Because of the tremendous amount of individual differences and the uncertainty of the nature of these errors, we did not analyze them systematically. However, the overall pattern is consistent with the argument that the Kanji Stroop task is much more difficult than the Kana Stroop task. The mean errors committed in the Kanji and Kana conditions are 5.42 and 2.75 , respectively.

2. Two recent experimental reports (Hatta, 1981; Tsao, Wu, \& Feustel, 1981) came to our attention after the submission of this paper. Both studied the Stroop effect in different writing systems with a visual half-field experimental paradigm. Both found greater Stroop interference in Chinese logographs than in sound-based scripts (i.e., Kana and English words in the two experiments, respectively).

(Received for publication October 15, 1980; revision accepted March 14, 1981.) 